\title{
Calculation of glacier volume from sparse ice-thickness data, applied to Schaufelferner, Austria
}

\author{
Andrea FISCHER \\ Institute of Meteorology and Geophysics, University of Innsbruck, Innrain 52, A-6020 Innsbruck, Austria \\ E-mail: andrea.fischer@uibk.ac.at
}

\begin{abstract}
In order to develop and evaluate a method for the determination of glacier volume from ice-thickness data, the volume of Schaufelferner, Austria, is calculated (1) by manual interpolation of ground-penetrating radar (GPR) data based on measurements at 36 locations in 1995, (2) by manual interpolation of 144 GPR measurements acquired for a higher-resolution estimate in 2003 and 2006, (3) by multiplying the mean of the measured ice-thickness data by the glacier area, (4) by automatic kriging of the 1995 GPR data and (5) by application of area/volume scaling algorithms to the Austrian glacier inventory data of 1969, 1997 and 2006. The so determined glacier volumes are compared with the ice-volume changes calculated from digital elevation models (DEMs) of the Austrian glacier inventories. The manually interpolated volumes based on the 1995 and 2003/06 GPR data yielded a volume loss only slightly different from volume loss calculated from the glacier inventories of 1997 and 2007. Other methods were not able to reproduce the volume losses of the glacier inventory DEMs. To assess the accuracy of deriving ice-thickness changes with GPR, repeated ice-thickness measurements at the same locations were carried out between 2005 and 2008.
\end{abstract}

\section{INTRODUCTION}

Knowledge of glacier ice volume is essential for the development of projections of glacier extent, sea-level rise and mountain hydrology. Since direct measurement of glacier volume requires extensive fieldwork, only a small fraction of the world's glaciers and ice caps have been surveyed, and much work is being devoted to deriving methods to calculate current and future glacier volumes. Estimates of the present ice volume contained in mountain glaciers, provided by Lemke and others (2007), differ considerably. Sea-level change corresponding to the different volume estimates ranges from 0.15 to $0.37 \mathrm{~m}$.

Since the mid-1990s, the introduction of lightweight ground-penetrating radar (GPR) systems has allowed largescale ground-based measurements of ice thickness on temperate alpine glaciers (e.g. Narod and Clarke, 1994). Airborne ice-thickness radar techniques have been used over mountain glaciers (e.g. Macheret and Zhuravlev, 1982; Dowdeswell and others, 1984). Several different techniques may be used to estimate glacier volume from ice-thickness measurements. The simplest, but least accurate, is to estimate the total ice volume as the product of the glacier area and the average of the measured ice-thickness values. In order to derive the spatial distribution of the volume, either the ice-thickness or the bedrock elevation data are interpolated. The interpolation can involve additional information, such as topographic data and ice-dynamics considerations (e.g. Erasov, 1968; Brückl, 1970; Funk and others, 1994; Bauder and others, 2003; Binder and others, 2009). Lentner (1999), for example, determined the ice thickness of some Austrian glaciers by assuming ellipticalshaped glacier beds.

Based on glacier volume estimates derived from measured values of ice thickness, several empirical algorithms have been developed to calculate ice volume from easily observed ice surface quantities (e.g. Driedger and Kennard, 1986; Chen and Ohmura, 1990; Meier and Bahr, 1996;
Trabant, 1997). Bahr and others (1997) theoretically investigated a relationship between glacier surface area and volume and found that scaling factors can vary significantly (e.g. from one glacier to the other or on the same glacier under different conditions).

In order to add spatially distributed volume data to the Austrian glacier inventory (Lambrecht and Kuhn, 2007), 53 glaciers were surveyed in 1995, 2006 and 2007 (Span and others 2005; Fischer and others, 2007) using GPR. In 1995, due to low computing and battery capacities and a limited project and time budget, the density of measurements per glacier was sparse. Ice thickness was measured along several profiles on each glacier. A sketch of a typical spatial distribution of samples is shown in Figure 1. On average, ice thickness was measured at a density of 33 points per $\mathrm{km}^{2}$, ranging from 7 to 220 points per $\mathrm{km}^{2}$ depending on the size of the glacier and complexity of the terrain. In very steep, crevassed, avalanche- or ice-/rockfall-affected areas, no measurements were carried out. Surveyed glaciers included large valley glaciers as well as small, flat cirque glaciers and steep, crevassed glaciers of medium size. As much as possible, we calculated glacier volume using the same technique for every glacier in order to obtain a homogeneous dataset. Since the spatial resolution of GPR measurements varied, it seemed most practical to construct the bedrock manually, based on the measured values of ice thickness and the topographic data of the 1998 Austrian glacier inventory. This method is demonstrated for Schaufelferner, Stubai Alps. In addition to the sparse data acquired early in the campaign, GPR data with higher spatial resolution were acquired in 2003 and 2006. These are used to estimate the accuracy of ice volume calculated from the sparse data. Different scaling algorithms and automatic gridding of the bottom topography data were also used to calculate the volume of Schaufelferner. The volumes are compared and set in relation to recent ice-thickness changes in order to decide whether the accuracy is at least in the same order of magnitude as the thickness changes. 


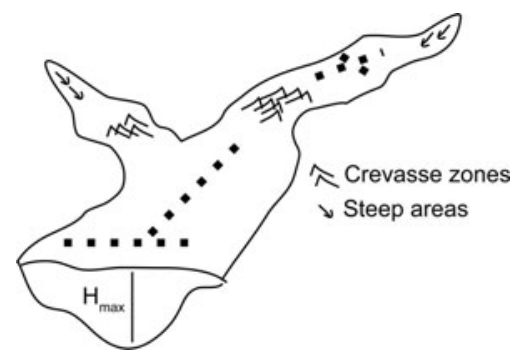

Fig. 1. Typical spatial distribution of ice-thickness measurements on Austrian glaciers during the GPR campaigns of 1995-2007

Schaufelferner had an area of $1.4 \mathrm{~km}^{2}$ in 1997 and covered elevations between 3200 and $2700 \mathrm{~m}$. The orthoimage and elevation contours (1997) are shown in Figure 2. In recent years, very few crevasses have been observed since the flow velocities have decreased (personal communication from W. Müller, 2005). The glacier is exposed to the north and has a low surface slope. On Schaufelferner, several independent campaigns measuring ice thickness have been carried out. Locations where GPR data were acquired in 1995, 2003 and 2006 are shown in Figure 2. Between 2005 and 2008, repeat measurements were performed to investigate temporal changes and the accuracy of the system. The location of these repeat measurements is indicated in Figure 2. Digital elevation models (DEMs) of Schaufelferner were acquired from airborne photogrammetry in 1969 (Patzelt, 1980) and 1997 (Lambrecht and Kuhn, 2007) and airborne laser scanning in 2006 (Government of Tyrol). All DEMs use the Austrian Gauss-Krüger system.

\section{METHODS}

\section{Radar equipment}

The data were collected using the miniature high-power impulse transmitter developed by Narod and Clarke (1994). Until 1998, the signal was received with an oscilloscope card in a notebook computer. After 1998, a Fluke 105B oscilloscope was used as receiver. The dipole antennas with non-reflecting resistive loading (Wu and King, 1965; Rose
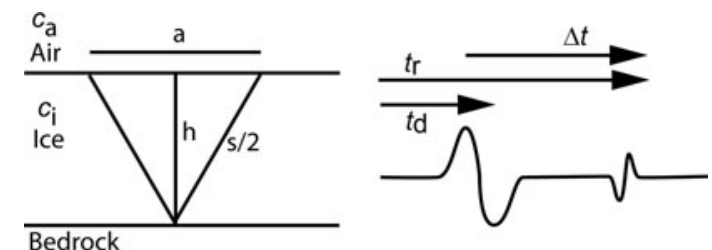

$c_{\mathrm{b}}$

Fig. 3. Measurement geometry assumed for calculating ice thickness.

and Vickers, 1974) were built in-house. Corresponding to the antenna half-lengths, $I$, of 15 and $25 \mathrm{~m}$, the central frequencies, $f_{\mathrm{c}}$, are 6.4 and $3.8 \mathrm{MHz}$ respectively according to

$$
f_{\mathrm{C}}=\frac{96}{l} \mathrm{MHz}
$$

(personal communication from B. Narod, 1996). The centreto-centre separation, $a$, of the antennas was equal to the antenna half-length during most field campaigns. The ice thickness was calculated from the measured time difference, $\Delta t$, between travel time of the signal transmitted through the air, $t_{\mathrm{a}}$, and the signal reflected from the ground, $t_{\mathrm{r}}$ (Fig. 3).

The propagation velocity was not determined at the measurement locations but was assumed to be $168 \mathrm{~m} \mathrm{\mu s}^{-1}$ (Narod and Clarke, 1994; Bauder, 2001). This value is well within the range given in the literature (e.g. $167.7 \mathrm{~m} \mathrm{\mu s}^{-1}$ (Glen and Paren, 1975); $168.5 \mathrm{~m} \mathrm{\mu s}^{-1}$ (Robin, 1975); $169.0 \mathrm{~m} \mathrm{ss}^{-1}$ (Kovacs and others, 1995)). The path of the reflected signal has length $s$, where

$$
s=t_{\mathrm{r}} c_{\mathrm{i}}
$$

with $t_{\mathrm{r}}$ travel time and $c_{\mathrm{i}}$ the velocity of the signal in the ice.

Assuming a locally homogeneous plane-parallel ice block, the ice thickness, $h$, is given by

$$
h=\frac{1}{2} \sqrt{\left(\Delta t+\frac{a}{c_{\mathrm{a}}}\right)^{2} c_{\mathrm{i}}^{2}-a^{2}} .
$$

This equation is based on a geometric setting as indicated in Figure 3.
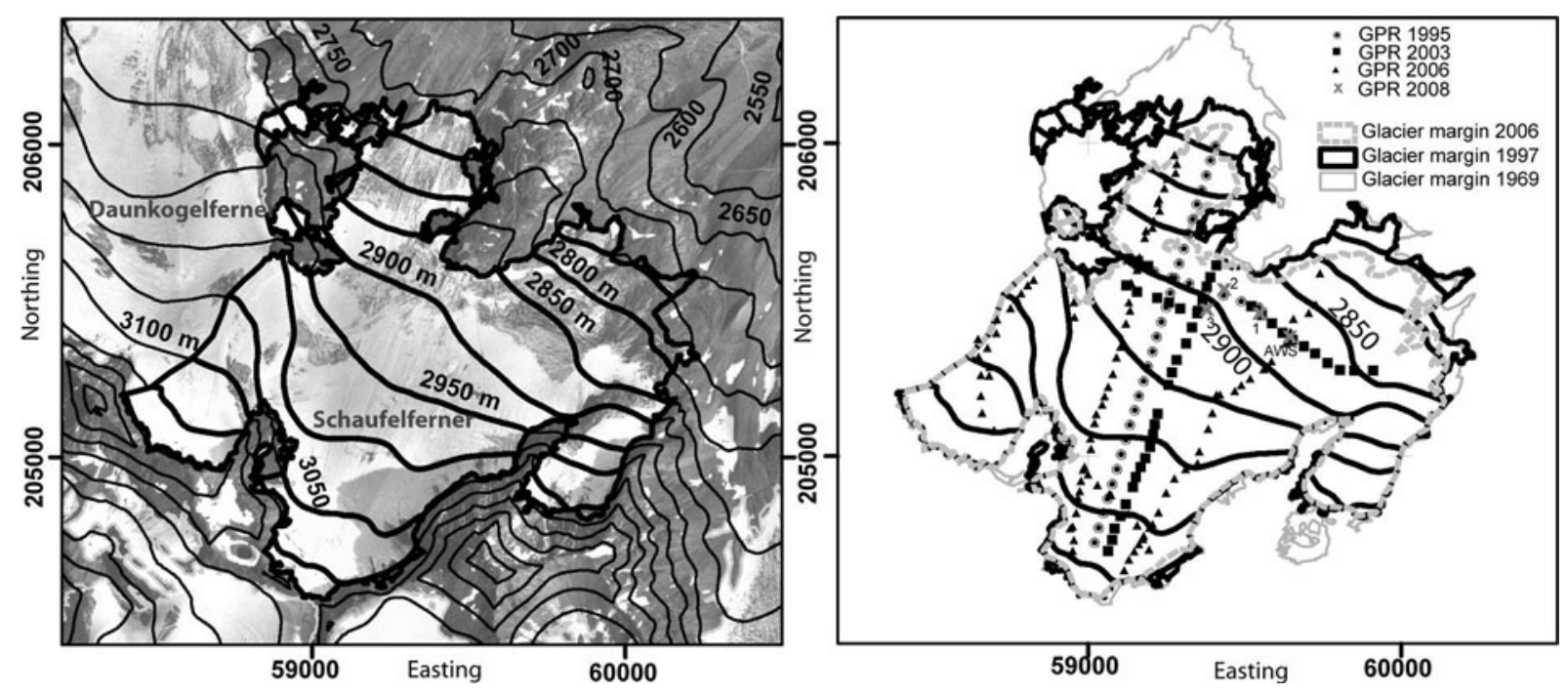

Fig. 2. Orthoimage contours of elevation in 1997 and glacier area in 1969, 1997 and 2006 for Schaufelferner, Stubai Alps. The locations of the ice-thickness measurements during the 1995, 2003 and 2006 campaigns and the repeat measurements in 2008 are indicated. 


\section{Data acquisition}

The GPR data on Austrian glaciers are ground-based, acquired mainly during the late winter months. The locations of measurements on the glacier surface were determined with an average accuracy of $\sim 10 \mathrm{~m}$ horizontally using a Garmin Summit global positioning system (GPS). The number of measurements is limited by the time and effort required in the field and for data processing, especially in the early years of the measurements when power supply was limited. Measurements are not located in a regular grid but on profiles along and across the glacier. During the earlier GPR surveys of Austrian glaciers, measurements were carried out with the aim of finding a maximum ice-thickness value on each glacier. Thus, the deepest location in a cross-profile was chosen as the starting point for a longitudinal profile. The focus on maximum ice thickness has the advantage that misinterpretation of ice thickness caused by bedrock undulations in the order of magnitude of ice thickness plays no role. After 2003, areas with shallow ice cover were also investigated and mapped, since these areas are important for the development of projections of glacier area. On average, the ice thickness was measured at 33 locations per $\mathrm{km}^{2}$. The GPR 1995 data of Schaufelferner can be considered 'typical' for the above-described data samples.

\section{Accuracy of ice-thickness measurements}

The accuracy of ice-thickness estimations from GPR measurements is determined by two factors: the accuracy of the measurement system and the properties of the ice and bedrock. For the first the resulting errors are small compared to the measured values. Depending on the scale used to display the data, the run time of the signal can be measured with an accuracy of $\pm 30 \mathrm{~ns}$. Four antennas are used, arranged in two pairs. The antennas coupled to the receiver are positioned parallel to the antennas coupled to the sender. Because of glacier surface undulations, we sometimes know the distance between antenna pairs to an accuracy of only $\pm 2 \mathrm{~m}$. For a typical run time of $1 \mu$ s the resulting accuracy of the calculated ice thickness is $\sim \pm 3 \mathrm{~m}$.

The second source of error is more difficult to quantify and can have far larger effects on the estimation of ice thickness. The internal structure of the glacier, including crevasses, internal boundaries and inhomogeneities, as well as topography and roughness of the bedrock, can cause large errors. In the case of multiple reflections, identification of the signal reflected from the bedrock can be difficult or even impossible. Bedrock undulations on the same order of magnitude as the ice thickness can lead to misinterpretation of the data.

We assume the glacier ice to be homogeneous, and firn layers and seasonal snow cover at the time of the measurement are neglected. Errors due to winter snow cover are expected to be smaller than $\pm 5 \mathrm{~m}$, and in most areas even lower. Sparse information on the thickness of firn layers on Austrian glaciers is available. From a firn pit on Kesselwandferner, Ötztal Alps, in the 1970s (Ambach and others, $1978,1995)$ it is estimated that the thickness of firn layers today varies between 0 and $\sim 20 \mathrm{~m}$. Haeberli and others (1982) estimated the error introduced by neglecting firn layers at $\sim 5 \%$. A short calculation using Equations (2) and (3) demonstrates the possible effect of neglecting firn layers, which causes an underestimation of ice thickness, and winter snow layers, which causes an overestimation of ice thickness. Assuming a signal velocity of $200 \mathrm{~m} \mathrm{ss}^{-1}$ in firn and $290 \mathrm{~m} \mathrm{\mu s}^{-1}$ in dry winter snow, the effects of neglecting a winter snow cover of $4 \mathrm{~m}$ and a firn layer of $30 \mathrm{~m}$ thickness compensate each other.

Maps and photos were used to determine larger-scale bedrock undulations, since ridges in the bedrock are often indicated by crevasse zones. We conclude that a good estimate for the measurement uncertainty of typical thicknesses (30-300 m) of Austrian glaciers will be in the order of $5-10 \%$ of the measured value. Single points exhibiting unfavourable geometry can show far larger deviations, also affecting the total glacier volume. Therefore the data were carefully controlled and the spatial interpolation was based on manually constructed contours of ice thickness. In very steep and/or crevassed areas, no measurements were carried out.

\section{VOLUME CALCULATION}

Since the method for determining the spatial distribution of ice volume is applied to a finite number of completely different types of glaciers with different sample density, the bedrock topography was constructed manually according to the measured ice-thickness and glacier inventory data. Glaciers with large crevasse zones especially exhibit sparse and not well-distributed ice-thickness data. A supervised method reduces the need to fill data gaps, as it becomes necessary for an automatic algorithm to be applied. Filling the data gaps by educated guess or automatic procedures involving ice dynamics creates at least two different categories of volume datasets without totally excluding subjective decisions.

The Austrian glacier inventory includes the glacier margins and DEMs of all Austrian glaciers between 1997 and 2002. At each GPR measurement position, the ice thickness was subtracted from the surface elevation from the glacier inventory DEM. The surface-altitude changes between the dates of the radar survey and the acquisition of the DEMs are within several meters. Figure 4 shows the change in surface elevation of Schaufelferner between 1997 and 2006.

Contours, at $20 \mathrm{~m}$ spacing, of bed topography were constructed according to the assumptions:

at the margin of the glaciers, including nunataks and rock outcrops, the ice thickness is zero.

the slope of periglacial rocks, but not debris near and under the ice, is approximately the same.

the ice thickness in crevassed zones is lower than in nearby areas exhibiting the same surface slope but no crevasses.

A bed topography for Schaufelferner was constructed based on the 1995 GPR measurements. The interpolation of the contours to calculate a raster format DEM of the bed topography was carried out in ArcGIS 9.3 using the Topo2Raster tool, which is based on the ANUDEM algorithm (Hutchinson, 1989; Hutchinson and Dowling, 1991). The method uses iterative finite-difference interpolation, which was designed to do 'intelligent interpolation' preserving natural structures such as drainage systems, ridges and hilltops. This algorithm allows inclusion, not only of contour input data, but also of point elevations and margins where the user can define the priority of different types of input data. 

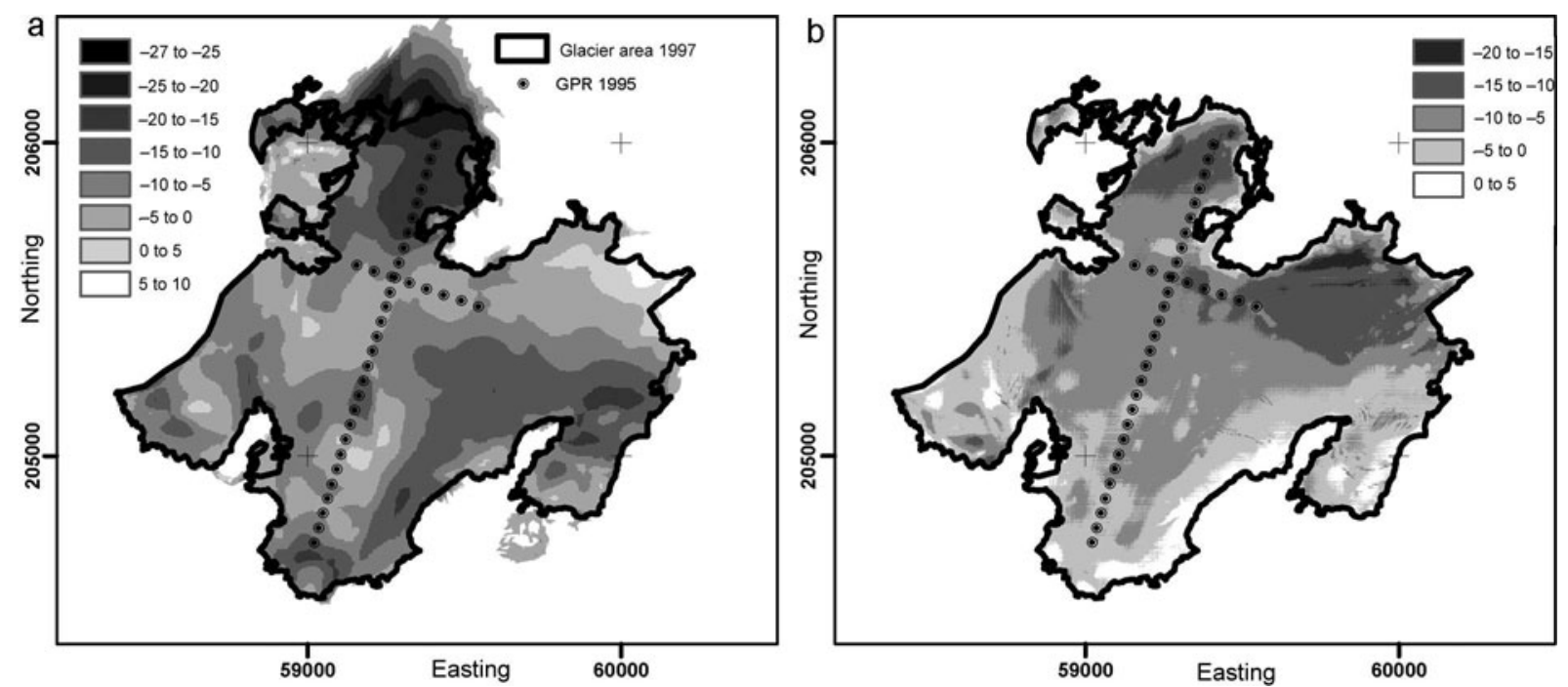

Fig. 4. Maps of ice-thickness change from 1969 to 1997 (a) and from 1997 to 2006 (b), calculated from the DEMs.

Applying Topo2Raster to the contours of bed topography and glacier margins, the total volume was found to be $0.043 \mathrm{~km}^{2}$, corresponding to an average ice thickness of about $30 \mathrm{~m}$ (Table 1). The $40 \mathrm{~m}$ contours of bed topography and the spatial distribution of ice thickness are shown in Figure 5 (GPR 1995 c; Table 1).

\section{ON THE ACCURACY OF THE VOLUME DETERMINATION}

Before volume data can be used in further investigations of glacier change, we need to know the magnitude of the volume error bar and the certainty of the spatial distribution of the ice mass. The requirements on the accuracy of the volume data, of course, depend on the type of investigation, but a good starting point is a comparison with average thickness changes on a timescale of, for example, a decade. The average ice thickness of Austrian glaciers has reduced by $1 \mathrm{ma}^{-1}$, averaged over the total glacier surface over the

Table 1. Volume $\left(\mathrm{km}^{3}\right)$ of Schaufelferner calculated from measured data and scaling algorithms for 1997. The volumes for 1969 and 2006 are calculated by subtracting the volume differences from the DEMs of 1969, 1997 and 2006 from the 1997 volume. The areas given $\left(\mathrm{km}^{2}\right)$ are used to calculate the mean ice thickness (Fig. 8)

\begin{tabular}{lccc}
\hline & 1969 & $\mathbf{1 9 9 7}$ & 2006 \\
\hline Volume based on: & & & \\
GPR 2003/06 c & 0.046 & $\mathbf{0 . 0 3 8}$ & 0.025 \\
GPR 2003/06 cp & 0.045 & $\mathbf{0 . 0 3 7}$ & 0.024 \\
GPR 1995 c & 0.051 & $\mathbf{0 . 0 4 3}$ & 0.030 \\
GPR 1995 p & 0.036 & $\mathbf{0 . 0 2 8}$ & 0.015 \\
Volume calculated after: & & & \\
Müller and others (1976) & 0.044 & $\mathbf{0 . 0 3 4}$ & 0.027 \\
Driedger and Kennard (1986) & 0.040 & $\mathbf{0 . 0 3 2}$ & 0.027 \\
Macheret and Zhuravlev (1982) & 0.109 & $\mathbf{0 . 0 8 9}$ & 0.074 \\
Chen and Ohmura (1990) & 0.059 & $\mathbf{0 . 0 4 6}$ & 0.037 \\
Bahr and others (1997)* & 0.052 & $\mathbf{0 . 0 4 0}$ & 0.032 \\
Area & 1.715 & $\mathbf{1 . 4 2 2}$ & 1.209 \\
\hline
\end{tabular}

${ }^{*}$ Schaufelferner is treated as a valley glacier; a multiplicative factor of 0.025 is assumed as 'proportionality'. past three decades (Lambrecht and Kuhn, 2007). This is of the same order of magnitude as the accuracy of a single icethickness measurement by GPR. To meet the requirement that decadal changes in ice thickness are resolved in the volume data, the accuracy of the ice volume should allow the calculation of the mean ice thickness with an accuracy of $\sim 10 \mathrm{~m}$. Therefore, the accuracy of the volume should be $10 \mathrm{~m}^{3}$ per $\mathrm{m}^{2}$ of glacier area in order to allow an interpretation of glacier volume changes.

If the ice-thickness measurements were distributed over the glacier on a regular grid, the mean ice thickness could be calculated as the average of the measured values, and the volume error bars would be directly related to the accuracy of the ice-thickness measurements. This is not the case, so the accuracy of the ice-thickness data does not give us any clue on the accuracy of the total volume. Assuming that a GPR measurement is representative of the ice thickness within a square of $100 \mathrm{~m} \times 100 \mathrm{~m}$, the 36 GPR measurements from 1995 will cover $25 \%$ of the area of Schaufelferner.

The completely independent GPR data of 2003/06 include 144 ice-thickness measurements which, on the above assumption, cover $100 \%$ of the area of Schaufelferner. These data were used to derive a volume which can be considered to be closer to reality. The deviation from this more realistic volume can be considered as the error bar on the 1995 volume estimation. In order to obtain a more reliable estimate of the variability of volumes derived from measurements, different methods were used for the volume determination, including automatic gridding. This resulted in an icethickness grid, which made it possible to compare not only the total volume, but also the ice-thickness distribution.

Additionally, the total volume was calculated using various scaling methods. The bandwidth of these estimates should give an indication of the degree to which results for an individual glacier can differ.

\section{COMPARING SPATIAL DISTRIBUTIONS OF ICE THICKNESS}

An automatic gridding was applied to the 1995 GPR data (GPR 1995 p, Table 1; Fig. 6a). For the unsupervised interpolation of the sparse data, the kriging algorithm implemented in the ArcGIS 9.3 Spatial Analyst toolbox 

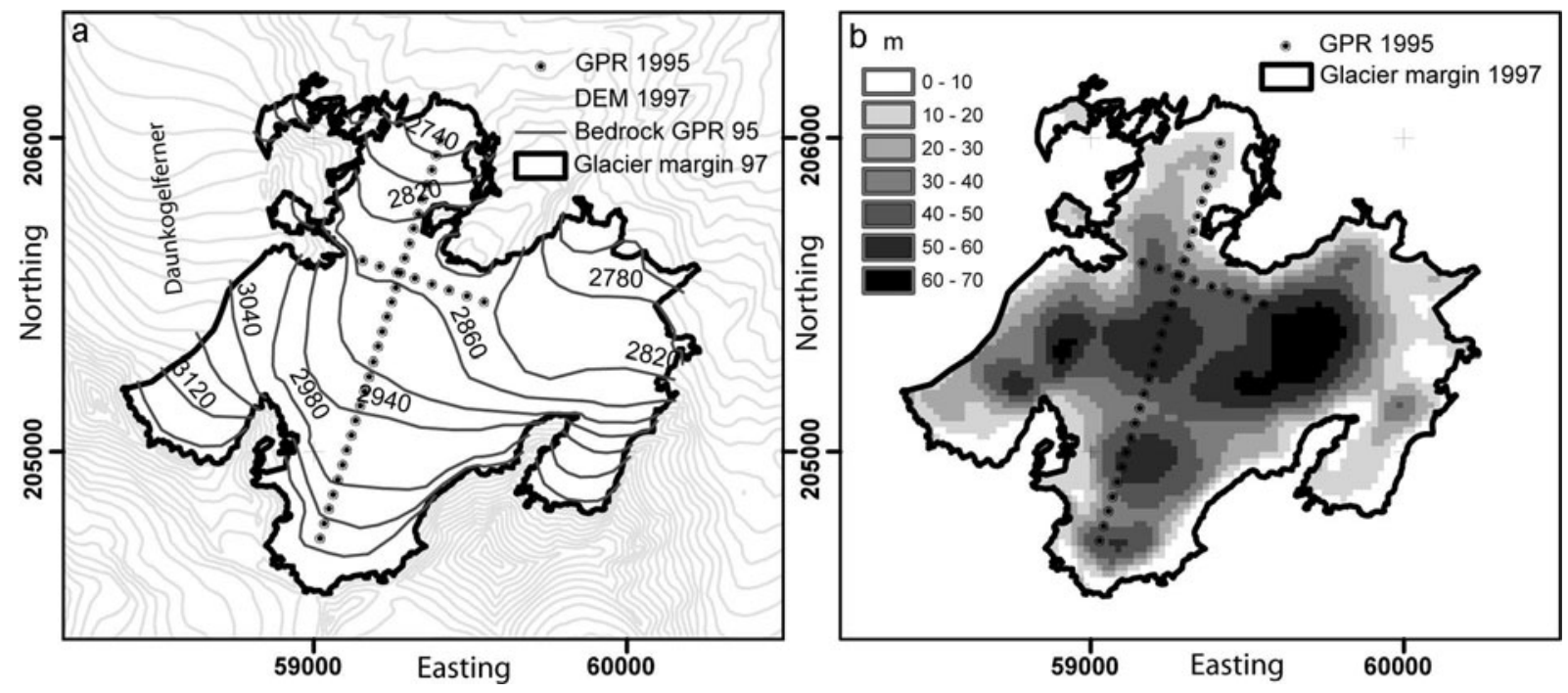

Fig. 5. Contours of bed topography (a) and calculated map of ice thickness (b) based on the GPR 1995 data.

(e.g. Oliver, 1990) was used. The ice thickness was taken to be zero at the margins, and a spherical semivariogram was assumed. From 144 ice-thickness measurements in 2003 and 2006, the volume was determined in the same way as above. The spatial distribution of the measurements and the topographic contours are shown in Figure 7. The contours were interpolated using the Topo2Raster tool, once based on contours and points (GPR 2003/06 cp; Table 1) and once based on contours only (GPR 2003/06 c; Table 1).

The maps of the ice-thickness distributions show high local differences in ice thickness (Fig. 6a-c). The maximum ice thickness of GPR 2003/06 c and GPR 2003/06 cp exceeds $100 \mathrm{~m}$ and is $\sim 30 \mathrm{~m}$ higher than for the GPR $1995 \mathrm{c}$ data. The automatic gridding produces negative values of ice thickness in areas without measurements; the maximum ice thickness is similar to the GPR 1995 c data. The differences between the GPR 1995 c and the GPR 2003/06 c data are largest in areas where no 1995 measurements were performed. The GPR 2003/06 cp and the GPR 2003/06 c data differ in areas without measurements and near the glacier margins. The results at the locations of the GPR measurements are similar. Since including the point measurements in the Topo2Raster algorithm seems to introduce a higher gradient to the margins and valley-like structures along the GPR profiles, the GPR 2003/06 c volume is considered as the 'true value' in the following section. The local differences between the 1995 volume and the 2003/06 volume calculations (Fig. 6d) far exceed the ice-thickness change from 1997 to 2006 derived from the DEMs (Fig. 4).

\section{COMPARING VOLUMES}

The volumes calculated from the 1995 GPR data show a larger dependency on the method applied, resulting in the highest $\left(0.043 \mathrm{~km}^{3}\right)$ and lowest $\left(0.028 \mathrm{~km}^{3}\right)$ volumes (Table 1). The GPR 2003/06 c $\left(0.038 \mathrm{~km}^{3}\right)$ and GPR 2003/06 cp $\left(0.037 \mathrm{~km}^{3}\right)$ volumes are much closer to each other. The accuracy of the volume for the GPR $1995 \mathrm{c}$ data is estimated to be the difference from the volume GPR 2003/06 c which is $\pm 0.005 \mathrm{~km}^{3}$ or $\pm 12 \%$.

The volume of Schaufelferner was also calculated according to Müller and others (1976), Macheret and Zhuravlev (1982), Driedger and Kennard (1986), Chen and
Ohmura (1990) and Bahr and others (1997). These areavolume scaling algorithms were developed from, and possibly designed for, different volume data and are usually applied to a large sample of glaciers. Nevertheless, it might be of interest to compare the mean ice thickness calculated for one glacier with measured data. The mean ice thickness modelled by the area-volume scaling algorithms decreases by $0-4 \mathrm{~m}$ between 1969 and 1997 and 1-2 m between 1997 and 2006. This is much less than calculated from the difference from the 1969, 1997 and 2006 DEMs. According to those data, the mean ice thickness reduced by $8 \mathrm{~m}$ between 1969 and 1997 and 5 m between 1997 and 2006 . This is about twice the difference between the GPR 1995 c and GPR 2003/06 c mean ice-thickness values. So the requirement that multi-year ice-thickness changes be resolved is fulfilled for volumes calculated from measured values for the total glacier area. Locally the deviation of icethickness data can be higher. For the volumes calculated with scaling methods, the deviation from the 'true' value ranges from 3 to $32 \mathrm{~m}$, with a mean of $14 \mathrm{~m}$, about twice the ice-thickness change in the two periods.

The mean ice thicknesses of Schaufelferner calculated according to the volumes and areas given in Table 1 are shown in Figure 8. For 1997, the values of the mean ice thickness vary between $20 \mathrm{~m}$ (GPR 1995 p) and $62 \mathrm{~m}$ (calculated after Macheret and Zhuravlev, 1982). The mean is $32 \mathrm{~m}$, which is $5 \mathrm{~m}$ more than the 'true' GPR 2003/06 c value. The means of the measured ice-thickness values are among the highest estimates for the mean ice thickness. The volume of Schaufelferner was analyzed in a previous study by Lentner (1999) based on the data of 1995 and assuming an area of $1475 \mathrm{~km}^{2}$. The mean ice thickness she calculated, based on three part-volumes, was $3 \mathrm{~m}$ higher than the GPR 1995 c volume.

\section{ON THE DETERMINATION OF VOLUME CHANGE BY GPR}

In order to investigate the potential of GPR for volumechange determination, repeat measurements were carried out on Schaufelferner. On one test site (AWS in Fig. 2), snow height and ice thickness were measured several times between 2003 and 2006 (Table 2). Between 2005 and 

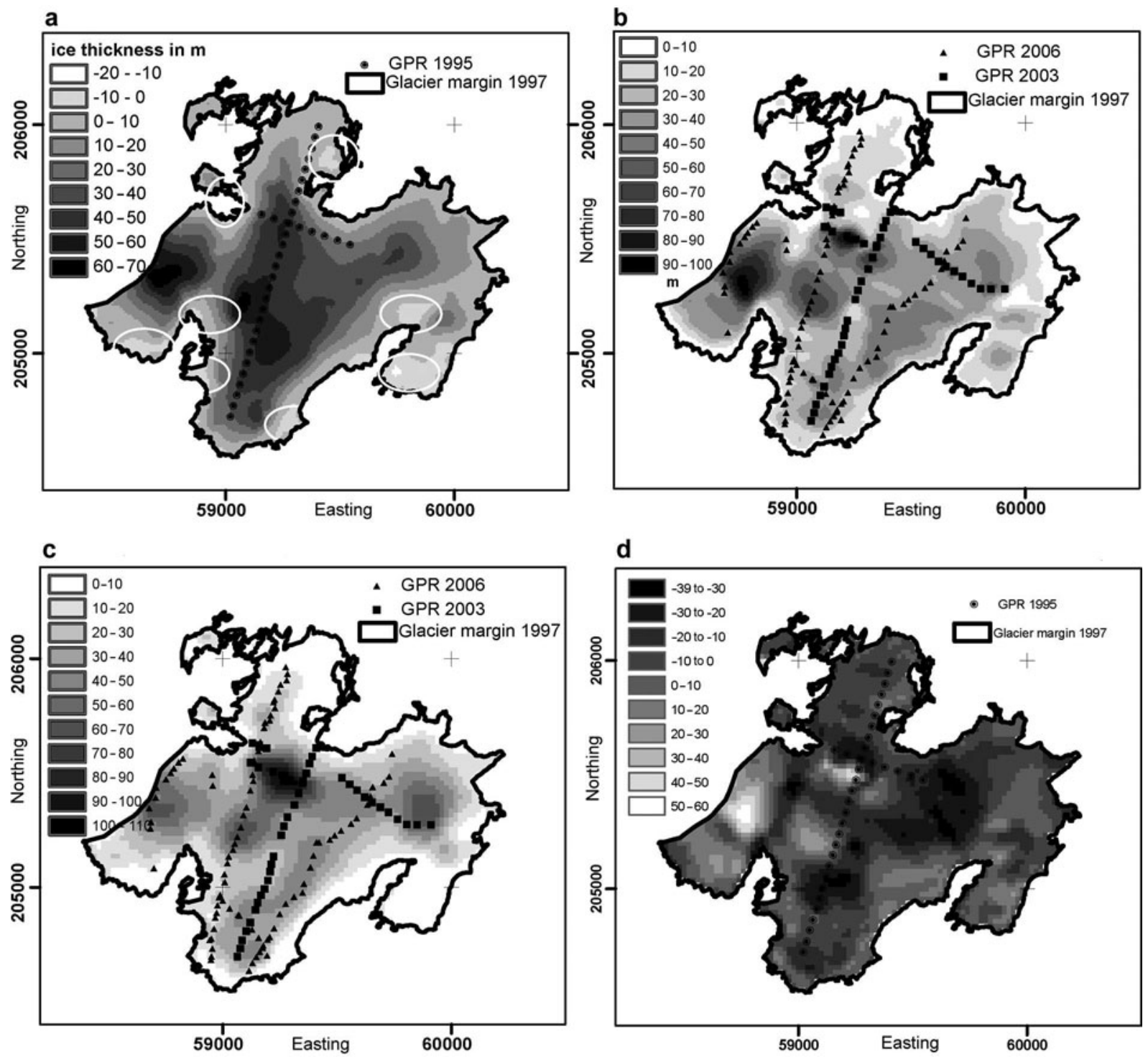

Fig. 6. (a-c) Maps of ice thickness calculated from (a) automatic gridding of GPR 1995 data; (b) interpolation based on contours of GPR 2003/06 data; and (c) interpolation of contours and points based on GPR 2003/06 data. (d) Map of differences in ice thickness between (b) and (c).

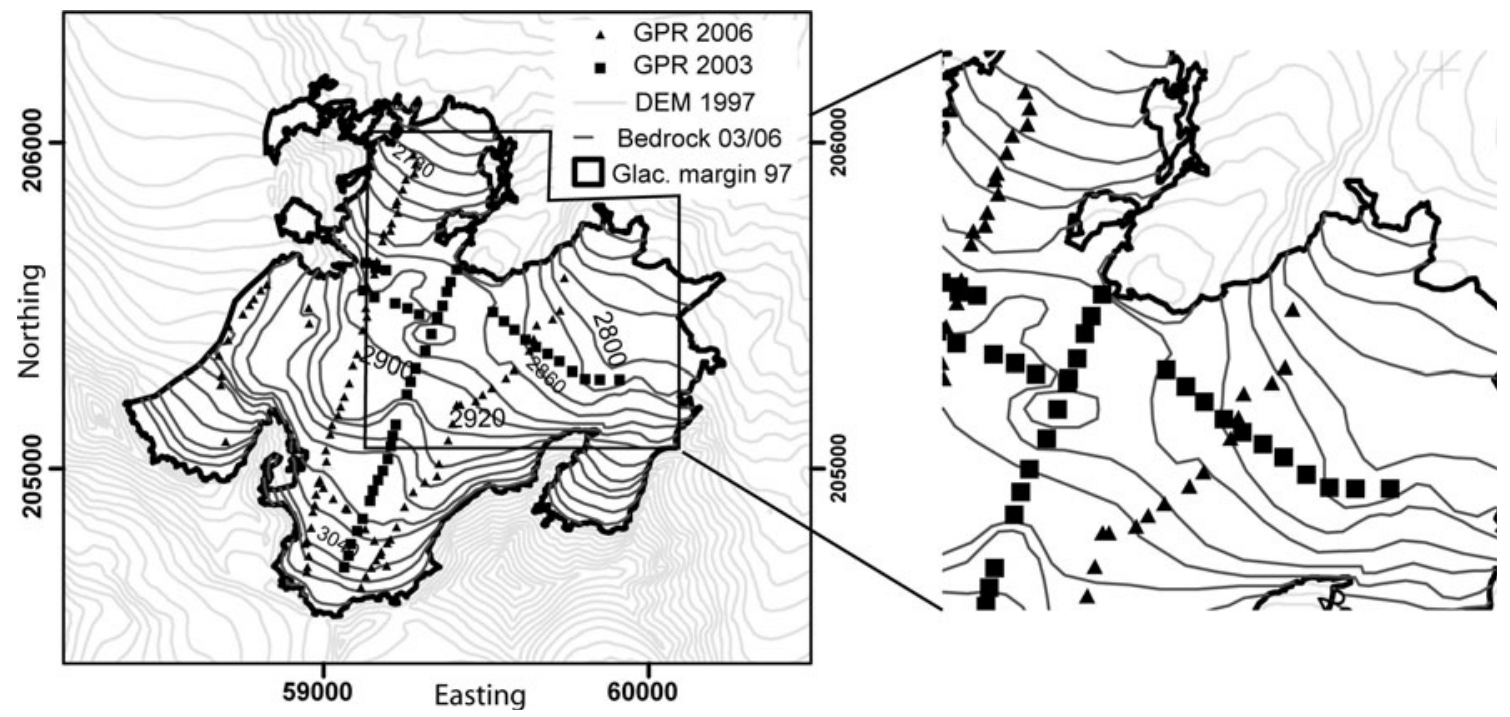

Fig. 7. Contours of bed topography based on the GPR 2003/06 data. 
2008, the position of the antennas was determined with a differential GPS (DGPS) with an accuracy $<1 \mathrm{~m}$. In 2003, the position was determined with lower accuracy.

The antennas were oriented in the direction of the slope. The surface slope is about $5^{\circ}$, so the difference in surface elevation between the antenna ends is about $3 \mathrm{~m}$. On 3 May 2005, the antennas additionally were turned by $90^{\circ}$, resulting in a decrease of $1 \mathrm{~m}$ in measured ice thickness. Between 2005 and 2008, the ice surface lowered by $7 \mathrm{~m}$ according to the DGPS measurements and $6 \mathrm{~m}$ according to the GPR data. According to the GPR measurements in 2005, the error of the ice thickness seems to be $<1 \mathrm{~m}$. Although the error in the positioning of the GPR is likely to be higher in 2003, with an estimated ice-thickness change of $\sim 3 \mathrm{~m}$ between 2003 and 2005, the measured ice thickness seems to have an accuracy of $<3 \mathrm{~m}$.

Three other locations (1, 2, 3 in Fig. 2) where the ice thickness was measured in 1995 and 2003 were revisited in 2008 (Table 3). Although the positions in 2008 were measured with DGPS, the ice thickness differs by up to $27 \mathrm{~m}$. The DEMs of 1997 and 2006 show a surface lowering by $9-11 \mathrm{~m}$ at the location of the GPR measurements. These data indicate that the reliability of ice-thickness change data derived even with exactly the same GPR system is highly dependent on the reproducibility of the measurement location. If the geometry is changed by, for example, changes in the surface slope of the glacier or the beamwidth of the GPR system used, the errors might be high.

\section{DISCUSSION AND OUTLOOK}

The accuracy of glacier volume calculated from sparse 1995 GPR data and including topographic information from the Austrian glacier inventory was of the same order of magnitude as the multi-year volume change. So, in order to resolve multi-year volume change for 53 Austrian glaciers, the manual construction of ice thickness based on the glacier inventory and sparse GPR data is sufficient. The choice of method has a greater impact on the results of the spatial distribution of volume than on the total volume. The local differences in the ice volumes were tens of cubic meters per square meter of glacier area compared to a variability of a few cubic meters per square meter of glacier area (Table 1). For applications, where the spatial distribution of volume is important, the method for volume

Table 2. Ice thickness and snow depth measured at AWS (Fig. 2) between 2003 and 2008

\begin{tabular}{lccc}
\hline Date & Glacier thickness & Snow height & Ice thickness \\
& $\mathrm{m}$ & $\mathrm{m}$ & $\mathrm{m}$ \\
\hline 14 Oct 2003 & $39^{*}$ & 1 & 38 \\
20 Apr 2005 & 40 & 2.42 & 38 \\
3 May 2005 & 40 & 2.10 & 38 \\
3 May 2005 & $39 *$ & 2.10 & 37 \\
24 May 2005 & 41 & 2.21 & 39 \\
8 Jun 2005 & 40 & 2.08 & 38 \\
29 Dec 2005 & 36 & 0.87 & 35 \\
16 Mar 2006 & 39 & 1.81 & 37 \\
29 Aug 2008 & 32 & 0 & 32 \\
& & & \\
\hline
\end{tabular}

*The measurement was performed with a $90^{\circ}$ rotated GPR system.

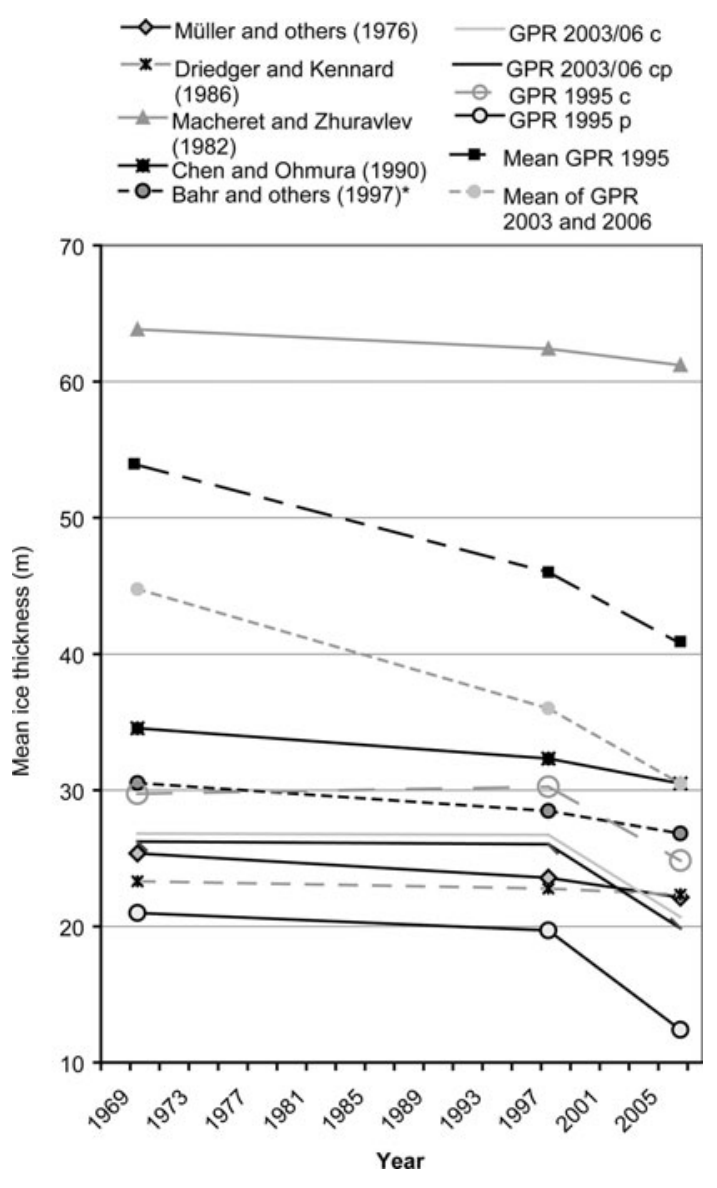

Fig. 8. Mean ice thickness for the volumes given in Table 1 for 1969, 1997 and 2006.

calculation has to be considered and described carefully. An increase in the spatial resolution of GPR measurements increases the accuracy of the spatial distribution of volume to a higher extent than the accuracy of the total volume.

Averaging the measured ice-thickness values overestimates the mean ice thickness of the glacier by up to $19 \mathrm{~m}$, much more than the ice-thickness change on a decadal timescale. The grade of overestimation of the ice thickness is highly dependent on the choice of the location of the GPR measurements.

Table 3. Ice-thickness and (when available) snow-depth measurements for locations 1-3 (Fig. 2) between 1995 and 2008

\begin{tabular}{lcc}
\hline & $\begin{array}{c}\text { Ice thickness } \\
\mathrm{m}\end{array}$ & $\mathrm{m}$ \\
& & \\
\hline Location 1: & & \\
20 Jun 1995 & 51 & 1 \\
14 Oct 2003 & 32 & 0 \\
29 Aug 2008 & 54 & \\
Location 2: & & 1 \\
20 Jun 1995 & 51 & 0 \\
14 Oct 2003 & 24 & \\
29 Aug 2008 & 40 & 1 \\
Location 3: & & 0 \\
14 Oct 2003 & 39 & \\
29 Aug 2008 & 28 & \\
\hline
\end{tabular}


The volumes derived by volume-area scaling algorithms are, apart from one, within a range of $\pm 5 \mathrm{~m}$ for 1997 . The application of these algorithms to the areas studied in 1969 and 2006 did not reproduce the measured volume changes between these years. A larger sample of glaciers will be investigated in a future project to find out whether the results for Schaufelferner are similar to those for other Austrian glaciers.

The accuracy of volume changes calculated from GPR measurements is highly dependent on the accuracy of the positioning. Therefore, the calculation of volume changes from surface elevation data seems to be a more costeffective and accurate way of monitoring volume change. This is especially true on a timescale of decades, since in the last decade GPR and DGPS technology have developed rapidly and it might not be possible to revisit a site with the same measurement configuration. In the light of global change, the determination of glacier volume will be an important subject of research in future.

\section{ACKNOWLEDGEMENTS}

This work was supported by the Austrian Academy of Sciences, Commission for Geophysics (head M. Kuhn). The scientific editor, T.H. Jacka, and two anonymous reviewers are acknowledged for valuable comments and suggestions.

\section{REFERENCES}

Ambach, W. and 9 others. 1978. Untersuchungen der Wassertafel am Kesselwandferner (Ötztaler Alpen) an einem 30 Meter tiefen Firnschacht. Z. Gletscherkd. Glazialgeol., 14(1), 61-71.

Ambach, W., J. Huber, H. Eisner and H. Schneider. 1995. Depth profiles of effective viscosities of temperate firn following from strain rate measurements at two firn pits (Kesselwandferner, Oetztal Alps, 1967-89). Cold Reg. Sci. Technol., 23(3), 257-264.

Bahr, D.B., M.F. Meier and S.D. Peckham. 1997. The physical basis of glacier volume-area scaling. J. Geophys. Res., 102(B9), 20,355-20,362.

Bauder, A. 2001. Bestimmung der Massenbilanz von Gletschern mit Fernerkundungsmethoden und Fliessmodellierungen: eine Sensitivitätsstudie auf dem Unteraargletscher. ETH-Zürich VAWE Mitt. 169.

Bauder, A., M. Funk and G.H. Gudmundsson. 2003. The icethickness distribution of Unteraargletscher, Switzerland. Ann. Glaciol., 37, 331-336.

Binder, D., E. Brückl, K.H. Roch, M. Behm, W. Schöner and B. Hynek. 2009. Determination of total ice volume and icethickness distribution of two glaciers in the Hohen Tauern region, Eastern Alps, from GPR data. Ann. Glaciol., 50(51), 71-79.

Brückl, E. 1970. Eine Methode zur Volumenbestimmung von Gletschern auf Grund der Plastizitätstheorie. Arch. Meteorol. Geophys. Bioklimatol., Ser. A., 19(3), 317-328.

Chen, J. and A. Ohmura. 1990. Estimation of Alpine glacier water resources and their change since the 1870s. IAHS Publ. 193 (Symposium at Lausanne 1990 - Hydrology in Mountainous Regions), 127-135.

Dowdeswell, J.A., D.J. Drewry, O. Liestøl and O. Orheim. 1984. Radio echo-sounding of Spitsbergen glaciers: problems in the interpretation of layer and bottom returns. J. Glaciol., 30(104), 16-21.

Driedger, C.L. and P.M. Kennard. 1986. Glacier volume estimation on Cascade volcanoes: an analysis and comparison with other methods. Ann. Glaciol., 8, 59-64.
Erasov, N.V. 1968. Metod opredelenija ob'ema gornych lednikov [Method for determining glacier volume]. Mater. Glyatsiol. Issled. Kazakhstan 14, 307-308. [In Russian.]

Fischer, N., M. Span, M. Kuhn, M. Massimo and M. Butschek. 2007. Radarmessungen der Eisdicke Österreichischer Gletscher. Band II: Messungen 1999 bis 2006. Österreich. Beitr. Meteorol. Geophys. 39.

Funk, M., G.H. Gudmundsson and F. Hermann. 1994. Geometry of the glacier bed of the Unteraarglacier, Bernese Alps, Switzerland. Z. Gletscherkd. Glazialgeol., 30(1-2), 187-194.

Glen, J.W. and J.G. Paren. 1975. The electrical properties of snow and ice. J. Glaciol., 15(73), 15-38.

Haeberli, W., H.P. Wächter, W. Schmid and C. Sidler. 1982. Erste Erfahrungen mit dem US Geological Survey - Monopuls Radioecholot im Firn, Eis und Permafrost der Schweizer Alpen. VAWE Arb. 6.

Hutchinson, M.F. 1989. A new procedure for gridding elevation and stream line data with automatic removal of spurious pits. J. Hydrol., 106(3-4), 211-232.

Hutchinson, M.F. and T.I. Dowling. 1991. A continental hydrological assessment of a new grid-based digital elevation model of Australia. Hydrol. Process., 5(1), 45-58.

Kovacs, A., A.J. Gow and R.M. Morey. 1995. The in-situ dielectric constant of polar firn revisited. Cold Reg. Sci. Technol., 23(3), 245-256.

Lambrecht, A. and M. Kuhn. 2007. Glacier changes in the Austrian Alps during the last three decades, derived from the new Austrian glacier inventory. Ann. Glaciol., 46, 177-184.

Lemke, P. and 10 others. 2007. Observations: changes in snow, ice and frozen ground. In Solomon, S. and 7 others, eds. Climate change 2007: the physical science basis. Contribution of Working Group I to the Fourth Assessment Report of the Intergovernmental Panel on Climate Change. Cambridge, etc., Cambridge University Press, 337-383.

Lentner, S. 1999. Volumsbestimmung von Gletschern der Ostalpen mittels Radardaten. (Diplomarbeit, Universität Innsbruck.)

Macheret, Yu.Ya. and A.B. Zhuravlev. 1982. Radio echo-sounding of Svalbard glaciers. J. Glaciol., 28(99), 295-314.

Meier, M.F. and D.B. Bahr. 1996. Counting glaciers: use of scaling methods to estimate the number and size distribution of glaciers of the world. CRREL Spec. Rep. 96-27, 89-94.

Müller, F., T. Caflisch and G. Müller 1976. Firn und Eis der Schweizer Alpen: Gletscherinventar. Zürich, Eidgenössische Technische Hochschule Zürich. (Geographisches Institut Publ. 57.)

Narod, B.B. and G.K.C. Clarke. 1994. Miniature high-power impulse transmitter for radio-echo sounding. J. Glaciol., 40(134), 190-194.

Oliver, M.A. 1990. Kriging: a method of interpolation for geographical information systems. Int. J. Geogr. Inf. Syst., 4(3), 313-332.

Patzelt, G. 1980. The Austrian glacier inventory: status and first results. IAHS Publ. 126 (Riederalp Workshop 1978 - World Glacier Inventory), 181-183.

Robin, G.de Q. 1975. Velocity of radio waves in ice by means of a bore-hole interferometric technique. J. Glaciol., 15(73), 151-159.

Rose, G.C. and R.S. Vickers. 1974. Calculated and experimental response of resistively loaded $\mathrm{V}$ antennas to impulsive excitation. Int. J. Electron., 37(2), 261-271.

Span, N., A. Fischer, M. Kuhn, M. Massimo and M. Butschek. 2005. Radarmessungen der Eisdicke Österreichischer Gletscher. Band 1: Messungen 1995 bis 1998. Österreich. Beitr. Meteorol. Geophys. 33.

Trabant, D.C. 1997. Ice volume modeling for mountain glacier and paleoglacial reconstruction. Mater. Glyatsiol. Issled. 81, 66-69.

Wu, T. and R. King. 1965. The cylindrical antenna with nonreflecting resistive loading. IEEE Trans. Antennas Propag., 13(3), 369-373. 